\title{
"A Compass During the Storm: Offering Students Critical Rigor for Polarizing Times"
}

\author{
Andrew Wender and Valerie D'Erman \\ APSA Teaching and Learning Conference 2020, Albuquerque NM
}

\author{
Session: Enhancing Data and Analytical Literacy \\ Conference Track: Teaching Research, Writing, and Information Literacy
}

\begin{abstract}
Teaching and learning in institutions of higher education is occurring, unavoidably, within the broader civic context of today's extraordinarily polarizing political times. In Canada, where we teach, public consciousness has recently been buffeted by a contentious 2019 federal election process, as well as impassioned debates over domestic and international matters ranging from the tension between Indigenous sovereignty and natural resource extraction, to Canada's uneasy positioning amidst the China-United States rivalry. Taken in the further light of the US's 2020 presidential campaign, made evermore fractious by the impeachment of President Trump, and global tumult spanning the horizon immediately beyond, we seek to help our students situate themselves with respect to, and above all thoughtfully assess these points of profound contention, without ourselves contributing to exacerbated polarization. We aim to offer students in our firstyear exploratory political science course a vital tool—critical rigor - for navigating, but not being inundated by the storm. This paper discusses our experiences in teaching our course, "The Worlds of Politics", as we have attempted to help students meaningfully engage in cognitive processes of critical analytic thinking, without undue infringement from their own, and least of all our, personal political biases.
\end{abstract}

\section{Authors}

Dr. Andrew Wender is an Assistant Teaching Professor in the Departments of Political Science and History at the University of Victoria.

Dr. Valerie D'Erman is a Sessional Instructor and Research Associate in the Department of Political Science as well as the European Studies Program at the University of Victoria. 


\section{Introduction}

Over approximately the past decade, we and our colleagues in the Department of Political Science, University of Victoria, Victoria, British Columbia, have been continually honing Political Science 103 ("The Worlds of Politics") as a gateway experience opening participants up to the intimate, multidimensional significances of politics for their lives. Politics is everywhere, we emphasize: from personal consumer choices that students make, to sweeping global currents like the populisms that are reshaping their world. From the channeling of power, as well as resistance to power, through the institutional and architectural structures of the university where they study, to timeless quandaries of justice and violence that manifest in innumerable, unique instances worldwide, while remaining reminiscent of such classic articulations as those from Thucydides. While doing so, we offer forth the discipline of political science as an analytic aid through which students can engage the world with enhanced awareness, sensitivity, and knowledge. It has become increasingly apparent, though, that the heart of this enterprise lies with cultivating skills of thought and communication that compel deep reflection on one's own cognitive presuppositions, and no less so on those informing the political science discipline itself. Served, thereby, is an overriding learning objective of promoting academic as well as civic ethics of humane respect, mutual understanding, and intellectual freedom; this, at a time when such ethics seem prey to endemic political polarization.

The compass of POLI 103 is set by an initial, three-week long unit in which we first situate politics as what W.B. Gallie termed an "essentially contested concept" (1955-56) — one that is perpetually remolded by the constant flux of language, thought, and power, such that we must always make ourselves keenly aware of the historical contingency of where we stand. Thereafter, our students are provided an introduction to political science research methods that grounds both positivist and constructivist accounts in a consideration of the philosophy of science, thereby underscoring how all modes of inquiry entail fundamental assumptions about the character of reality. To paraphrase Thomas Nagel, there is no "view from nowhere" (1986), least of all where one studies human consciousness and behavior. This unit coincides with the beginning of semester-long training in academic communication, developed as a series of short but stringent writing assignments. These, along with weekly tutorial participation, are used to impel students toward discovering, analyzing, and documenting the premises animating any political stance that they or others evince.

The balance of POLI 103 is flexibly organized around the disciplinary subfields, political theory, comparative politics, and international relations (IR). In each instance, we draw on historically enduring as well as timely, globally varied case studies, conveyed in differing media and experiential formats. A key aim is to underscore the inherent fluidity among, and contestable contours of these subfields, such as where we pose the self-reflexive question of whether political theory somehow embodies abstract ideas pointing toward a unifying notion of the good life"canonical" "Western" ideas, no less (Bhargava, 2012, pp. 3-55; Freeden \& Vincent, 2013)? Or, are the ceaselessly diverse lived expressions, experiences, and moral dilemmas of humankind's political lives the stuff of which all three subfields, and much else besides, are made simultaneously? Representative focal points include the ongoing resonances of Thucydides's 
History of the Peloponnesian War (Strassler, 1998); critical readings of nationalism, from its origins to today's worldwide populisms; Canadian-focused guest speakers addressing matters like Indigenous politics, and Canadian federalism, as well as a Member from British Columbia's Legislative Assembly; and viewing Errol Morris's 2003 documentary The Fog of War as a window into what former US Secretary of Defense Robert McNamara's life has to teach about the conflicting perspectives from which politics can be undertaken and judged, sometimes to devastating effect. In all events, the aim is helping our students to better orient themselves with strategies for intellectual and ethical responsibility, in a disorienting world that demands their care and commitment.

This paper conveys the successes and trials of our experiences in POLI 103 to date, with a focus on the challenges of cultivating self-reflective analytic outlooks during politically charged times, and on the opportunities available for fostering discussions that are deeply probing without devolving into unnecessary and counterproductive polemics. We propose some insights into the quandaries behind trying to introduce the discipline of political science within a thirteen-week period, and some practical strategies for helping students to differentiate between advocacy and analysis.

\section{Overview of course development}

Our Department began offering POLI 103 in Fall 2009, and during every Fall and Spring term since then, as a gateway course introducing students to the political science discipline through a subfield-based approach. Through Spring 2017, the course operated on a consistent model whereby one Departmental colleague served as course coordinator, and was the instructor of record as well as students' prime contact for matters like grading. At the same time, rotating teams of three colleagues from the Department's respective political theory, comparative politics, and IR sections came in to lecture on each of the subfields for several weeks at a time. Under this model, one of this paper's two authors served as the course coordinator between Fall 2015 and Spring 2017, while also handling political theory lecturing duties during Spring 2017. From the inception of POLI 103, each section of the course has had a large (anywhere between approximately 150200 students, sometimes more), diverse student enrollment comprising some current political science majors, as well as many enrollees from across UVic disciplines and faculties, or those who have not yet declared a major - all exploring to see whether the course, and in instances a prospective political science major, might be of interest to them. Also since the course's inception, instructors and students have been supported by rotating groups of approximately five teaching assistants who apply for the position from across various fields of study in the Department's MA and $\mathrm{PhD}$ program; generally speaking, the TAs have the demanding role of shepherding throughout the term two tutorial groups of approximately ten to twenty students each.

Beginning in Fall 2017, POLI 103 was revamped in an effort to enhance the course's vibrancy,

pertinence to a diversity of current political events spanning from the local to global levels, and pedagogical capacities at delivering the manner of critical thinking experience that we elaborate 
in this paper. Initially, the course shifted almost entirely from a subfield-based to a case-study based approach, before reintegrating the subfields during 2018-19, albeit to a significantly more flexible degree than had been the case between Fall 2009 and Spring 2017; as compared to the Fall 2009-Spring 2017 model, the subfields now function rather more as thematic and organizational frameworks within which to situate case studies and key, contemporary and historical political motifs. Another crucial dimension of the course redesign has been an added unit, taught during the first weeks of the term, covering critical approaches to the study of politics and the discipline of political science, including emphases on the relationship between politics and language, as well as material on the philosophy of science and political science research methodologies. Not least, the course's writing component was changed from a single, eight-page long traditional research essay, to several shorter assignments whose learning objectives and sequencing throughout the term are intended to enhance students' skills at the application of critical thinking to the study of the "Worlds of Politics".

On the redesigned model, which continues through the present with consistent updates, two Departmental colleagues collaborate on teaching the entire course. Both colleagues serve as equal partners in interacting with and grading the students, and together craft a curriculum within which each serves as the main lecturer on roughly half of the topics, consistent with their areas of teaching and research expertise. Each of the authors of this paper was integrally involved in the redesign process; the one of us who had served as course coordinator between Fall 2015 and Spring 2017 then co-taught the course with a further colleague during Fall 2017 and Spring 2018, and now, since Fall 2018, this paper's two authors have served as co-instructors of POLI 103.

\section{The urgency of teaching critical thinking during polarizing times}

It is axiomatic to our teaching that the world around us has always been, and likely always will be, politicized, and that tumultuous events have always framed political science instruction, however one might choose to depict the genealogy of the discipline (which would itself be an eminently worthy critical thinking exercise, albeit one falling outside the current purview). This being said, and while remaining vigilant against problematic modernist tendencies to pose one's own evanescent, present moment as the standard against which to judge the past, we seem to be experiencing an era whose rapid, largely unforeseen bewilderments and dislocations call out for the urgency of critique, above all "self-critique" (Hartog, 2017; Fassin \& Harcourt, 2019). Yet, paradoxically, such critique seems to be in characteristically short supply within an ostensibly "posttruth" world, wherein the "multiplication of so-called fake news and conspiracy theories" has merely "mimicked critical thinking", and rendered citizens more prone to becoming trapped within reverberating echo-chambers of confirmation bias (Fassin \& Harcourt, 2019, p. 3). Fassin and Harcourt offer an encompassing catalogue of the current global conditions against whose backdrop we teach, and that have served to help render civic society, in the form of our student body and far beyond, increasingly riven: 
The unexpected vote on Brexit, the unforeseen election of Donald Trump as president of the United States, the coming to power of authoritarian leaders in Italy and Austria, the illiberal turn of presumably democratic countries, such as Hungary and Poland, and the spectacular rise of nationalist and xenophobic parties in France, Germany, Denmark, Sweden, and the Netherlands [that] have shaken the Western world order. But this preoccupying polymorphic drift of politics has not spared the rest of the planet, from Egypt to Israel, from Turkey to India, from Venezuela to Brazil, from Thailand to the Philippines (Fassin \& Harcourt, 2019, p. 3).

Moreover, specific to our Canadian context of instruction, federal government efforts toward 'Truth and Reconciliation' with Indigenous peoples, and related imperatives for the decolonization and indigenization of universities, have intensified students' awareness of their own positionality vis-à-vis the historically entrenched truth claims and power structures of Canadian society (Government of Canada, "Truth and Reconciliation Commission of Canada").

Pedagogically speaking, a key significance of these global and national developments for our teaching in POLI 103 is that there now appears to be a more pronounced division among students, with respect to their varying perceptions of how deeply partisan politics ought to intrude upon the classroom. Emblematic of this divide is polarization over student perceptions of "social justice"what the term means and what it encompasses, as well as its relevance in the classroom. The present-day use of the term social justice, particularly on university campuses, is predominantly understood as "a series of taken-for-granted political propositions, including the centrality of race and gender in constructing inequality and the need for state intervention to overcome it" (Zimmerman, 2019). The conflation between social justice and partisan politics has, for many students, seemingly solidified the impression that those who care about social justice are politically 'left-wing', and consequently, that those who are 'right-wing' necessarily devalue social justice principles. With regard to teaching, the overlap between understandings of social justice and current political events also creates something of a political minefield for those professors who aspire to instruct in as politically neutral a style as possible. From our standpoint, the POLI 103 class is numerically large, diverse in all characteristics, and open to students from all departments and all levels of undergraduate university education. While our own professional commitment to instruct in a politically-neutral manner underscores our intellectual ambition of shaping a classroom environment wholly open for critical reflection, the size and diversity of our student body also, by our logic, obliges such neutrality. To interject personal, partisan leanings in any direction within a class of greater than 150 students would almost certainly be at odds with some percentage of the student body. Interjecting in such a fashion could, at the least, have a chilling effect on students who hold differing political opinions, and in the worst case would create accusations of 'power over' for grading and evaluation disagreements. A recent study by Giersch (2019) offers support to the supposition that students do indeed respond to professors' politics in a multitude of ways, and as a result suggests that political neutrality is the safest bet for attracting and retaining a broad set of students. This suggestion is also indirectly supported by Turner (2019), who advises that the current politicized trend within the discipline of sociology is being 
accompanied both by a narrowing of the field, and the self-selection of students to those who wish to prioritize activism over scientific analysis.

The exercise of teaching a political science class in a politically-neutral manner is indispensable to our endeavors in teaching critical thinking. From the outset, we have in mind the Greek etymological origin of criticism, krinein, connoting judgment and discernment, cognitive faculties that can only be cultivated if students are given the free space, and encouragement, to participate in genuine dialogical thinking that demands the constant questioning of one's own presuppositions, in conjunction with openness to other possibilities (Reese, 1996, p. 149). While, as might be expected, we spend time on the Socratic historical embodiments of critical dialogue, we are as eager to emphasize that, notwithstanding the frequent tendencies of modern, 'Western' political communities and political science to imagine themselves as embodying the intellectual DNA of ancient Athens, the Greek tradition holds no monopoly on critical thinking. If anything, we wish for POLI 103 to authentically, if by no means exhaustively, evoke multiple 'worlds' of politics. This means inspiring students toward deep, respectful engagement with fundamentally alternative visions of political life, thereby ameliorating one's own potential tendencies toward hunkering down into one's own viewpoint - a typical, if not necessarily unique trait of our social-media fuelled, echo-chamber age (Tully, 2016).

Critical thinking has been variously defined as "the capacity to work with complex ideas whereby a person can make effective provision of evidence to justify a reasonable argument" (Moon, 2008, p.128), or a set of skills developed for the evaluation of interpretations to decide what to believe or what action to take (Fisher, 2001). In seeking to further our students' appreciation for these practices, we work to demonstrate the process of evaluating and assessing competing arguments in action, such as when we describe, and mention possible challenges to, theoretical assumptions underlying the ideas of foundational authors, while also elucidating the historical context for these ideas. Consider, for example, the way in which John Locke's late seventeenth-century argument for the free individual's all-important natural right to mix one's labor with common property, and thereby create private property - long imagined as a noble pillar of modern liberalism - has more recently been critiqued by those who regard Locke has having actively abetted the colonial abnegation of Indigenous ownership (Locke, 2009, pp. 285-302). Moreover, in the light of Canadian public concerns for Indigenous sovereignty, this particular example has great currency, and has arguably even become de rigueur, within a Canadian university classroom. In this vein, one can appreciate how the aspiration toward presenting competing interpretations of political phenomena can be readily misperceived, at the same time, as itself a partisan choice within the current era of politicization. Illustrating with a decidedly different sort of ideological instance, to discuss the legal impeachment process against the Trump administration without making disparaging comments about the President, is to some students the equivalent of declaring oneself to be an avid Trump-supporter. Or, to discuss the tenacity of nationalism as a form of selfdetermination from the time of the Treaty of Westphalia to present-day incarnations of nationalist expression is to invite students to consider arguments that they may have been politically socialized to believe are unpleasant or even incorrect. Such perceptions are sometimes further reinforced by student experiences in other classrooms: Viteritti (2019) writes that "With the 
election of Donald Trump, my approach has now changed. Some things are not up for debate... Those of us who teach politics have a responsibility to enunciate basic values and explain why they are fundamental in a fair and open democratic society", while Clancy \& Bauer state that "teaching political science through diversity-focused discourse will help cultivate student-scholar activists" (2018, p.543). Such perspectives approach the construct of social justice as a given component of basic morality, rather than as a political conception that has been molded to serve different interests across time and space. While we do not seek to criticize instructors who choose to foreground the objective of social justice in the classroom, we offer that our experience in a very large group of predominantly first-year students who encompass a wide variety of political viewpoints - including even the apolitical - underscores the soundness of engaging students in critical thinking without our adhering to any one ideological platform. Doing so, we hope, creates a baseline foundation whereby students might be more receptive to the exercise of juggling competing arguments simultaneously.

\section{Lessons from POLI 103 thus far}

In our efforts to not just explain the need for critical thinking, but also to model it as a process for our students, we have found it helpful to design course components around assignments geared toward different kinds of cognitive evaluation exercises. We also seek to make transparent to our students what we are trying to achieve with the course's learning objectives, and why. At the outset of the semester, we describe POLI 103 as an exploration of the 'worlds' of politics in both the literal and the figurative sense, to include not only different regions and communal expressions of the world, but also varying theoretical approaches and methodologies. Moreover, we proceed to encourage students to actively critique those predominating perspectives on the study of politics that we convey to them, and to ponder the ways in which those perspectives are themselves reflective of distinct, first principles and changing political environments-from the ostensibly (yet debatably) authoritative scientific nature of modern positivism, to the postcolonial-era surge of constructivism, to the tentacular political potencies, and epistemological transformations, marking the "Big Data" algorithms of their own age (O'Neil, 2017). We state explicitly that our goal is not to superimpose specific political opinions or to prompt heated debates in the classroom, and that our intention is not to make our own opinions or biases known to our students. We also acknowledge that this is a difficult, and perhaps sometimes impossible, endeavor, as our own sources of education and institutional milieu have fundamentally shaped our academic practices. In numerous iterations of the course, we have noticed that students seem to respond positively to these up-front instructor statements. Some enrollees have taken the opportunity to ask us during the term's opening class whether our textbook or any of our readings is prescribing a particular viewpoint or political opinion. We do our best to answer honestly, generally to the effect of, we are not seeking to choose readings that advance such a viewpoint or opinion, but please do your best to sus out whatever underlying postures sources might seem to suggest. Further, coinstructing this class has particular advantages; our respective answers to such questions offers an immediate demonstration to the class of how the two of us might each offer an assessment of the potential bias in the readings. During the course of the semester, we have noticed that numerous 
students have tried to draw out a direct political opinion from either one of us with their questions in class. Our usual response is to remind students that our own personal opinion is not immediately germane to their learning and critical thinking, and to then steer them into considering the competing arguments surrounding the situation in question. To date, we have received overwhelmingly positive feedback with this strategy.

We ask the students to complete three writing assignments in POLI 103, which are deliberately varied in terms of what they ask from students. The first assignment is what we call a 'News Journal', which we employ as a "low stakes" writing assignment (Elbow, 1997) to get students comfortable with writing and responding. Here, we ask students to document over a five-day period the news that they consumed and their reaction to it. We emphasize that we do not want students to change their usual behavior, and as such do not require that they respond to any particular kind of news or focus on any specific source. Rather, we use this assignment to offer students a simple platform by which to receive feedback on their writing, grammar, and citation habits; just as important, this assignment dovetails with our unit on methods, in which we discuss constructs of reliability and expertise in sources as well as the vetting of methods and data in political science research. Further, the assignment follows from our initial considerations of politics as an "essentially contested concept", meaning that we do ask the students to apply their learning thus far, by reflecting on whatever might be distinctly political about the news that they have chosen - a relatively easy call for them if a story is about, say, Kim Jong Un, but an increasingly crucial explanatory task, if by no means less politically relevant, if it is perhaps about Colin Kaepernick, instead. Beyond this, the first assignment very deliberately does not require research or critique of arguments. In this vein, the 'low stakes' are evident in the simplicity of the task. This has proven to be helpful in engaging students in a conversation about news and sources (not least, the enormous impact of social media on our consumption of information), and connections between information, its conveyance, and the politics of language.

The news journal also offers something of a 'relief valve' allowing students to freely offer their reactions and opinions to the news that they are relating. We assure students that we do not grade or judge their opinion or their choice of news; the assignment is evaluated on adherence to the writing and sourcing criteria, together with a short presentation of their journal that acts as an icebreaker exercise during their first tutorial group discussion. This stands in contrast to the second assignment, which we call a 'Short Analytical Paper'. This second assignment is much more demanding and comprises what we consider to be the "high stakes" writing assignment of the semester (Elbow 1997). We provide students with a list of ten potential topics, all of which we update each semester, and all of which refer to a salient, current political debate or policy choice with practical ramifications. Some examples of recent topics include:

- Should statues be removed and/or should names of buildings be changed to reflect current perceptions (for instance, removing the statue of John A. MacDonald from downtown Victoria, or the statue of Robert E. Lee in Charlottesville VA)? 
- Concerning climate change, should governments levy a tax on individuals based on personal consumer choices (such as flying in an airplane, driving vehicles, having children, eating meat, etc.)?

- Does the United States' recent drone strike against Iranian Major General Qassim Soleimani advance legitimate policy objectives?

- Is the rise of populist and far-right right parties around the world a cause for concern or a valid democratic shift in ideological trends?

- In considering the idea of "sovereignty", please explain the competing perspectives on recent protests and the pro-democracy movement in Hong Kong.

Students are to outline the different viewpoints on their topic: how the issue might be defined, what the different perspectives are, and, if applicable, what the different proposed policies are. Emphasis is placed on explaining the perspectives using scholarly sources, and on evaluating the strengths and weaknesses of competing arguments. Students are asked to conclude by presenting a critical assessment of the various perspectives that they have presented, basing the logic of the assessment on the overview of positions provided in their paper. The goal is for students to provide a balanced view of both (or more) sides, without promoting one particular side or foregrounding one's own opinion.

We find that this assignment causes more uncertainty and apprehension in students than any other component of the semester, including the midterm and final exams. Students are consistently nervous about finding appropriate sources, and about the level of 'balance' they are offering between perspectives. We have noticed that the more provocative the topic, the more difficulty students have in adhering to the assignment criteria. This was particularly evident with a topic on gender equality ("Are mandatory quotas for gender and/or minority representation in a parliament (or any kind of decision-making assembly) a way of strengthening democratic legitimacy?") and a topic on gender orientation ("What are the arguments in support of a SOGI-inclusive (Sexual Orientation and Gender Identity) curriculum in BC [British Columbia] schools, and what are the arguments against?"). In both cases, students who chose either topic struggled to outline the argument of less-progressivist ideological perspectives; in one instance, a student explicitly stated that they would rather receive a lower mark than offer an objective explanation of why some groups objected to a SOGI curriculum.

What we have gleaned from this second assignment is that it is simultaneously the most important and least-favored writing exercise of the course. We have learned to incorporate prior student experiences into our explanation of the criteria to the class, making clear that the exercise of providing competing perspectives by no means suggests anything about an individual's actual preferences. We have also found it useful to directly engage students on the experience of critical thinking before and after submission of the assignment to gauge their assessment of the experience. While not all students readily appreciate the invitation to approach ideas with attention to inquiry and revision, many do respond positively to the exercise of divorcing the notion of 'criticality' from simple negativity or complaint. At present, our assessment of this assignment is that it is 
invaluable as much as it may be disliked, precisely because it asks students to focus on what is rational and demonstrable through intellectual self-discipline (Çavdar \& Doe, 2012).

Our third writing assignment targets the application of theory to practice. Students are asked to watch the documentary The Fog of War (Morris, 2003), a movie conveying "eleven lessons" from the life of the controversial former US Secretary of Defense Robert McNamara (1961-68). Working from this basis, students are to outline a few examples of how specific situations described in the film might exemplify (in the sense of tending to confirm, negate, or otherwise) some of the dominant assumptions underlying competing theoretical streams within the IR subfield of political science. We provide the students initial food for thought within class by together watching three vignettes from The Fog of War that are notable for the complex, strategic and moral dilemmas that they convey: one involving the 1962 Cuban Missile Crisis standoff between the US and Soviet Union; a portion in which McNamara relates his administrative role, as a young World War II-era military official, in initiating the extraordinarily destructive Allied fire-bombings of Japanese urban centers during Winter 1945; and a piece on the Vietnam War, in which McNamara shares the epiphany that whereas the US regarded that conflict as falling amidst the broad global rivalries of the Cold War, their Vietnamese opponents regarded it both as a civil war, and an anticolonial struggle for existential survival. Distinct from the less formal atmosphere of the first news journal assignment, where students are free to convey whatever opinions they wish, and different, as well, from the research-based analysis of the second assignment, this writing assignment concentrates on having students deeply engage with theoretical assumptions and thoroughly demonstrate their practical, often internally conflictual implementation. We assess

critical rigor in this assignment by asking students to clearly make links between theory and practice. Moreover, we ask them to avoid making generalizable statements such as "I feel like..." or "It looks like...", and to concentrate on the description of select events in the film to support their application of theory. Our central takeaway from this assignment is that students respond well to having an assigned focus for the 'practice' component of the exercise. In addition, and similar to the second assignment, students often have difficulty engaging in concepts that they find unpalatable. The regularity with which students write that realist IR theory is harsh and that social constructivist theory is congenial is telling from a pedagogical perspective; those who have difficulty with the process of inquiry and revision inherent in the critical thinking exercise are sometimes likely to associate the illustration of concepts in an ideologically neutral manner as being inherently unpleasant.

\section{Conclusion}

The exercise of teaching political science at the undergraduate level, in the vein of Gallie's "essentially contested concepts", is necessarily and fundamentally a process of simultaneous instruction, engagement, and dialogue. Our experience developing and co-teaching the current incarnation of our POLI 103 "The Worlds of Politics" undergraduate course has been instrumental in demonstrating the challenge of undertaking this exercise in highly polarized political moments, as well as in revealing the absolute importance of this endeavor for the development of critical 
thinking tools in our students. Students come into our class with a wide range of personal political preferences as well as a varied array of ideas on how politics ought to be approached and conveyed; as such, what we aim to provide them with in POLI 103 is the experience of using the cognitive method of critical rigor as something of a guiding compass during highly polarizing times.

In attending to this, our experiences to date have led us to develop a threefold approach toward the responsibility of engaging our students in critical thinking practices. The first is to guide our instruction with the aim of political neutrality on matters of importance-both local and international, current and historical. We do this in part to demonstrate to our students the process of engaging with dialectical - that is, evaluative and analytical-discourse on different case studies and enduring topics as a separate process from the expression and exercise of personal activism. We also do this to create the opportunity for all students to critically exercise their analytical skills without fear of evaluator retribution from any potential partisan contrasts with their instructors. The second approach is the design of assignments that approach critical thinking from different cognitive strategies: our short news journal assignment asks students to first document their usual news consumption behavior and to then explore the assumptions inherent in the news we read and the sources and medium in which the information is grounded; the analytical paper provides a deep-dive challenge into a research-based exercise of analytical balance between competing political perspectives, some of which are highly charged; and the application of IR theories to the 'practice' of IR as exemplified in the documentary The Fog of War provides an opportunity for students to assess the origin and evolution of the theoretical assumptions inherent in different real-world examples.

The notion of 'critical thinking', which we explain to students as being an repeated process of questioning their own presuppositions as well as those of others, can be a difficult concept to engage with, let alone to teach and evaluate within the very short time-frame of 13 weeks. The intensified polarization of the current political climate, from local to global levels, not only exacerbates many of the divisive tensions inherent in partisan politics; it also puts a fine point on the delicate balance between the aim of objective analysis and the social construct of objectivity in and of itself. Our work with students in POLI 103 has become an invigorating exercise in inculcating a willingness to discern among competing arguments, frameworks, and ideologies. 


\section{References}

Bhargava, R. (2012). What is Political Theory and Why do We Need It? New Delhi: Oxford University Press.

Çavadar, G., \& Doe, S. (2012). Learning through writing: teaching critical thinking skills in writing assignments. PS: Political Science and Politics, 45(2): 298-306. https://doi:10:1017/S1049096511002137

Clancy, K. A., \& Kelly Bauer, K. (2018). Creating student-scholar-activists: discourse instruction and social justice in political science classrooms. New Political Science, 40(3): 542-557. DOI: $10.1080 / 07393148.2018 .1489091$

Elbow, P. (1997). High stakes and low stakes in assigning and responding to writing. In M. D Sorcinelli \& P. Elbow (Eds.), Writing to learn: Strategies for assigning and responding to writing across the disciplines. San Francisco: Jossey-Bass.

Fassin, D. \& Harcourt, B.E. (2019). Introduction. In D. Fassin and B.E. Harcourt (Eds.), A Time for Critique. New York: Columbia University Press.

Fisher, A. (2001). Critical thinking: An introduction. New York: Cambridge University Press.

Freeden, M. \& Vincent, A. (2013). Introduction: The study of comparative political thought. In M. Freeden \& A. Vincent (Eds.), Comparative Political Thought: Theorizing practices. London and New York: Routledge.

Gallie, W.B. 1955-56. Essentially Contested Concepts. Proceedings of the Aristotelian Society 56: 167-198.

Giersch, J. (2019). Professors' politics and their appeal as instructors. PS: Political Science and Politics. DOI: https://doi.org/10.1017/S104909651900194X

Government of Canada. (2019). Truth and Reconciliation Commission of Canada. https://www.rcaanc-cirnac.gc.ca/eng/1450124405592/1529106060525\#chp1 ） (last accessed January 25, 2020).

Hartog, F. (2017). Regimes of Historicity: Presentism and Experiences of Time, S. Brown (Trans.). New York: Columbia University Press.

Journell, W. (2019). Professors, are you hiding your politics? Bad idea. The Chronicle of Higher Education, Special Reports (22 September 2019). https://www.chronicle.com/article/Professors-Are-You-Hiding/247170/ 
Locke, J. (2009). Two Treatises of Government, P. Laslett (Ed.). Cambridge: Cambridge University Press.

McLaughlin, A. C., \& McGill, A. E. (2017). Explicitly teaching critical thinking skills in a history course. Science \& Education, 26: 93-105. https://doi.10.1007/s11191-017-9878-2

Moon, J. A. (2008). Critical thinking: An exploration of theory and practice. London: Routledge.

Morris, E. \& Williams, M. (Producers), \& Morris, E. (Director). (2003). The fog of war: Eleven lessons from the life of Robert S. McNamara [Motion picture]. United States: Sony Pictures Classics.

Nagel, T. (1986). The view from nowhere. New York: Oxford University Press.

O’Neil, C. (2017). Weapons of Math Destruction. New York: Broadway Books.

Reese, W.L. (1996). Dictionary of Philosophy and Religion, Eastern and Western Thought. Atlantic Highlands, New Jersey: Humanities Press.

Strassler, R. (Editor) (1998). The Landmark Thucydides: A Comprehensive Guide to the Peloponnesian War. New York: Touchstone.

Tully, J. (2016). Deparochializing Political Theory and Beyond: A Dialogue Approach to Comparative Political Thought. Journal of World Philosophies, 1: 51-74. https://scholarworks.iu.edu/iupjournals/index.php/jwp/article/view/623/79

Turner, J. H. (2019). The more American sociology seeks to become a politically-relevant discipline, the more irrelevant it becomes to solving societal problems. The American Sociologist, 50: 456-487. https://doi.org/10.1007/s12108-019-09420-5

Viteritti, J. P. (2019). How Trump changed the way I teach. The Chronicle of Higher Education, Special Reports (22 September 2019). https://www.chronicle.com/article/How-TrumpChanged-the-Way-I/247169/

Zimmerman, J. (2019). 'Social Justice', according to whom? The Chronicle of Higher Education, Special Reports (22 September 2019). https://www.chronicle.com/article/Social-Justice$\underline{1247171 /}$ 